\title{
Penerapan Metode SMART dalam Seleksi Penerima Bantuan Sosial Warga Masyarakat Terdampak COVID-19
}

\author{
Bambang TJ Hutagalung1, Elida Tuti Siregar'1, Juanda Hakim Lubis ${ }^{2, *}$ \\ ${ }^{1}$ Program Studi Teknik Informatika, Universitas Potensi Utama, Medan, Indonesia \\ ${ }^{2}$ Program Studi Teknik Informatika, Universitas Medan Area, Medan, Indonesia \\ Email: ${ }^{1}$ bambangtjh@gmail.com, ${ }^{2}$ elidatuti87@gmail.com, ${ }^{3}$ juandahakim@gmail.com \\ Email Penulis Korespondensi: juandahakim@gmail.com
}

\begin{abstract}
Abstrak-Perkumpulan Wanita (PW) Tabita menghadapi kendala dalam menentukan kriteria yang objektif dalam menentukan warga masyarakat terdampak Covid-19 untuk bantuan sosial yang akan disalurkan agar tepat sasaran. Hal ini dikarenakan tidak adanya sistem yang sistematis dan terukur dalam menentukan warga yang layak sebagai penerima bantuan sosial tersebut. Untuk membantu PW Tabita tersebut maka perlu dibentuk suatu sistem yang mampu memberikan output rekomendasi pemilihan warga masyarakat yang paling layak sebagai penerima bantuan sosial. Kriteria pemilihan penerima bantuan sosial merujuk pada pemenuhan beberapa unsur, yaitu : status pekerjaan, jumlah penghasilan perbulan, banyak tanggungan, status tempat tinggal, Status tarif listrik, peserta asuransi, dan peserta PKH (Program Keluarga Harapan). Metode Simple Multi-Attribute Rating Technique (SMART) adalah metode yang diterapkan dalam penelitian ini. Hasil penelitian menunjukkan bahwa penentuan bobot yang tepat pada setiap kriteria sangat mempengaruhi hasil perhitung an terhadap rekomendasi pemberian bantuan dana sosial bagi masyarakat terdampak Covid-19. Kemudian agar dapat memperoleh hasil yang lebih akurat maka perlu dilakukan uji validitas terhadap kriteria untuk memperoleh kriteria yang lebih tepat sesuai dengan kebutuhan seleksi kelayakan penerima bantuan dana sosial bagi warga masyakat terdampak Covid-19 dari PW Tabita.
\end{abstract}

Kata Kunci: Covid-19; Bantuan Sosial; Sistem Pendukung Keputusan; Simple Multi-Attribute Rating Technique

Abstract-The Tabita Women's Association (PW) faces obstacles in determining objective criteria in determining community members affected by Covid-19 for social assistance to be distributed so that they are right on target. This is due to the absence of a systematic and measurable system in determining which citizens are eligible as recipients of social assistance. To help PW Tabita, it is necessary to establish a system capable of providing output recommendations for the selection of the most appropriate community members as recipients of social assistance. The criteria for selecting social assistance recipients refer to the fulfillment of several elements, namely: employment status, monthly income, number of dependents, residence status, electricity tariff status, insurance participants, and PKH (Family Hope Program) participants. The Simple MultiAttribute Rating Technique (SMART) method is a method applied in this research. The results showed that determining the appropriate weight for each criterion greatly influenced the results of the calculation of the recommendation for providing social funds for people affected by Covid-19. Then in order to obtain more accurate results, it is necessary to test the validity of the criteria to obtain more precise criteria in accordance with the eligibility needs of receiving social funds for community members affected by Covid-19 from PW Tabita.

Keyword: Covid-19; Social Assistance; Decission Support System; Simple Multi-Attribute Rating Technique

\section{PENDAHULUAN}

Perkumpulan Wanita (PW) Tabita adalah perkumpulan yang dibentuk di GKPI JK Pulo Brayan Medan dimana anggotanya merupakan wanita yang telah menikah yang selalu aktif dalam berbagai kegiatan sosial. Kegiatan tersebut dengan melakukan pengumpulan dana sosial, baik secara pribadi, membuat suatu event, membuat proposal, dan lain sebagainya. Dana sosial ini dihimpun bertujuan untuk diberikan bagi warga jemaat yang kurang mampu secara khusus dan kepada masyarakat di sekitar gereja secara umum.

Sejak pandemi Covid-19 melanda dunia dan secara khusus melanda di Indonesia, tentu telah memberikan dampak yang sangat luas bagi seluruh warga masyarakat luas. Secara khusus di kota Medan, banyak warga masyarat yang kehilangan pekerjaan, omset (penghasilan) menurun drastis, kebutuhan meningkat, dan sebagainya. Oleh karena itu, PW Tabita ingin ikut serta mengambil bagian untuk meringankan beban warga masyarakat di sekitar gereja walaupun berbeda latar belakang suku, ras, dan agama.

Warga masyarakat calon penerima bantuan sosial yang terdampak Covid-19 jumlahnya lebih banyak dibandingkan dengan jumlah bantuan sosial yang tersedia. Sedangkan pemilihan warga masyarakat penerima bantuan sosial tersebut berdasarkan kriteria yang dimiliki oleh setiap Warga Calon Penerima bantuan sosial.

Hal ini menjadi masalah yang dihadapi oleh PW Tabita selaku pemberi bantuan sosial, dimana harus melakukan pemilihan yang spesifik, terukur, dan akurat supaya tepat sasaran kepada warga masyarakat yang ditargetkan. Agar membantu pemilihan warga masyarakat penerima bantuan tersebut, maka perlu dikembangkan suatu sistem yang memberikan rekomendasi warga masyarakat yang paling layak sebagai penerima bantuan sosial. Sistem yang dibangun ini dapat diaplikasikan dalam membantu PW Tabita untuk menentukan warga masyarakat yang paling layak sehingga dapat mengurangi rasa kecewa bagi warga masyarakat yang tidak terpilih untuk menerima bantuan sosial tersebut. Kriteria pemilihan warga masyarakat Warga Calon Penerima penerima bantuan sosial berdasarkan beberapa kriteria, yaitu: status pekerjaan, jumlah penghasilan perbulan, banyak tanggungan, 
status tempat tinggal, Status tarif listrik, peserta asuransi, dan peserta PKH (Program Keluarga Harapan).

Metode dalam menyelesaikan permasalahan pada pengambilan keputusan memiliki beberapa jenis, diantaranya ELECTRE (Elimination Et Choix Traduisant la Realite), metode AHP (Analytical Hierarch Process), metode SMART (Simple Multi-Attribute Rating Technique), metode TOPSIS (Technique for Order Preference by Similarity Ideal Solution) dan metode sistem pengambil keputusan lainnya. Sundari dalam penelitiannya menggunakan metode ELECTRE dalam menentukan SNMPTN Jalur Undangan [1], sedangkan Adelin dalam penelitiannya menerapkan metode TOPSIS dalam memilih kegiatan UKM (Usaha Kegiatan Masyarakat) yang paling tepat [2], sedangkan Septiadi dan Sarmini dalam penelitiannya menggunakan metode AHP untuk memilih kelayakan pemberian kredit [3]. Namun, peneliti memilih menggunakan sistem pendukung keputusan dengan metode SMART (Simple Multi-Attribute Rating Technique) dalam menyelesaikan permasalahan yang PW Tabita terkait pemilihan warga masyarakat penerima bantuan sosial yang tepat. Pemilihan metode ini berdasarkan pada kesederhanaan dan fleksibelitas yang dimiliki oleh metode SMART dalam memberikan keputusan pemilihan yang tepat [4]-[6].

Metode SMART merupakan metode pengambilan keputusan yang bertujuan untuk mengumpulkan informasi tentang semua data yang berkaitan dengan beberapa atribut (multi atribut) dan beberapa kriteria (multi kriteria). Parameter ini menggunakan data sebelum dan data sesudah, dari data tersebut akan dihasilkan klasifikasi dan keterkaitan antara data satu dengan data lainnya sehingga hasil akhir akan didapatkan solusi hasil terbaik [7]. Teknik pembuatan keputusan multi-atribut ini merupakan suatu prosedur perhitungan matematis yang membantu pengambil keputusan dalam mengevaluasi dan memeringkat secara otomatis pada banyak kemungkinan alternatif. Peran seorang pembuat keputusan sangat penting, khususnya dalam memilih suatu solusi yang sesuai dengan tujuan yang telah dirumuskan. Setiap pilihan solusi yang dirumuskan merupukan kumpulan atribut dan setiap atribut memiliki nilai-nilai. Nilai ini yang selanjutnya akan dirata-ratakan dengan perbandingan tertentu. Setiap atribut memiliki bobot dengan tujuan untuk mendeskripsikan seberapa krusial atribut tersebut dibandingkan dengan atribut lain. Pemberian bobot dan perangkingan ini digunakan untuk menilai setiap pilihan solusi agar memperoleh preferensi terbaik dalam memecahkan masalah yang dihadapi [8][9].

Hasil dari pengambilan keputusan dari metode SMART ini juga dapat mempermudah PW Tabita selaku pemberi bantuan sosial dalam menentukan warga masyarakat sebagai penerima bantuan sosial yang paling layak. Hal ini sesuai dengan hasil penelitian Guntur dan Yanto yang menemukan bahwa metode SMART dalam melakukan proses perangkingan terhadap alternatif kriteria yang telah dipilih sebagai hasil penilaian yang didasarkan pada kebutuhan pemilihan kelayakan penerima bantuan pengembangan usaha pangan masyarakat, diantaranya izin, pengalaman kegiatan bisnis, memiliki Anggaran Dasar dan Anggaran Rumah Tangga, ada atau tidaknya mesin penggiling, serta luas gedung penyimpanan barang [10]. Penelitian sejenis juga dilakukan oleh Nasution pada penelitiannya dalam melakukan penilaian kinerja karyawan, menunjukkan bahwa metode SMART terbukti cepat dan efisien dalam pengolahan data, serta dapat memberikan hasil output informasi dalam bentuk laporan hasil seleksi karyawan berprestasi [11]. Sadly, dan tim penelitiannya juga menemukan bahwa metode SMART dapat digunakan dalam meningkatkan pengambilan keputusan kelompok dalam pemilihan vendor yang memenuhi stakeholder. Mereka juga menemukan bahwa model SMART yang digunakan dalam penelitian dapat mengurangi waktu yang dibutuhkan untuk pemilihan vendor dan proses pengambilan keputusan menjadi lebih sistematis [12]. Namun berdasarkan hasil penelitian di atas, output dari proses sistem pendukung keputusan ini tidak dapat dijadikan sebagai suatu keputusan yang wajib digunakan, hal ini dikarenakan sistem pengambilan keputusan (SPK) hanyalah suatu sistem pemberi alternatif keputusan, sedangkan pihak pengambil keputusan tetap memegang kuasa penuh dalam pengambilan keputusan, sehingga melalui penggunaan metode SMART sebagai metode pengambil keputusan dapat menghemat waktu (efisiensi waktu) serta memberikan bantuan kepada pihak pengambil keputusan dalam menentukan keputusan terbaik.

\section{METODE PENELITIAN}

\subsection{Metode SMART}

Berikut langkah-langkah dalam proses metode Simple Multi Attribute Rating Technique (SMART), yaitu:

1. Langkah 1 : Menentukan jumlah kriteria.

2. Langkah 2 : sistem secara default memberikan skala 0 - 100 berdasarkan prioritas yang diinputkan kemudian dilakukan normalisasi.

$$
\text { Normalisasi }=\frac{w_{j}}{\sum w_{j}}
$$

Keterangan

$\mathrm{w}_{\mathrm{j}}$ : bobot suatu kriteria

$\sum w_{\mathrm{j}}$ : total bobot semua kriteria

3. Langkah $3:$ memberikan nilai kriteria untuk setiap alternatif.

4. Langkah 4 : hitung nilai utility untuk setiap kriteria. 


$$
\mathrm{u}_{\mathrm{i}}\left(\mathrm{a}_{\mathrm{i}}\right)=100=\frac{(\text { Couti-Cmin) }}{(\text { Cmax }- \text { Cmin })} \%
$$

Keterangan :

$\begin{array}{ll}\mathrm{u}_{\mathrm{i}}\left(\mathrm{a}_{\mathrm{i}}\right) & : \text { nilai utility kriteria ke } 1 \text { untuk kriteria ke-i } \\ \mathrm{Cmax} & : \text { nilai kriteria maksimal } \\ \mathrm{Cmin} & : \text { nilai kriteria minimal } \\ \text { Cout I } & : \text { nilai kriteria ke-i }\end{array}$

5. Langkah 5 : hitung nilai akhir setiap kriteria atau masing - masing.

$$
\mathrm{u}_{\mathrm{i}}\left(\mathrm{a}_{\mathrm{i}}\right)=\sum_{j=1}^{m} W j U i(a i)
$$

\subsection{Tahapan Penelitian}

Penelitian ini menerapkan sistem pendukung keputusan dengan metode Simple Multi-Attribute Rating Technique (SMART). Metode SMART memanfaatkan proses pengukuran multi-kriteria yang menghasilkan pemeringkatan terhadap pengukuran terbaik sesuai dengan nilai saran yang diberikan [12]. Metode ini merupakan metode pengambil keputusan yang didasarkan pada ide bahwa setiap solusi pilihan terdiri dari sejumlah indikator yang memiliki nilai-nilai dan setiap indikator tersebut memiliki bobot yang memberikan gambaran sejauh mana esensial indikator tersebut dipadankan dengan indikator lainnya. Pemberian bobot ini digunakan untuk menilai setiap alternatif agar diperoleh alternatif yang terbaik [7], [13]. Prosedur penelitian ini dapat dilihat pada Gambar 1 berikut:

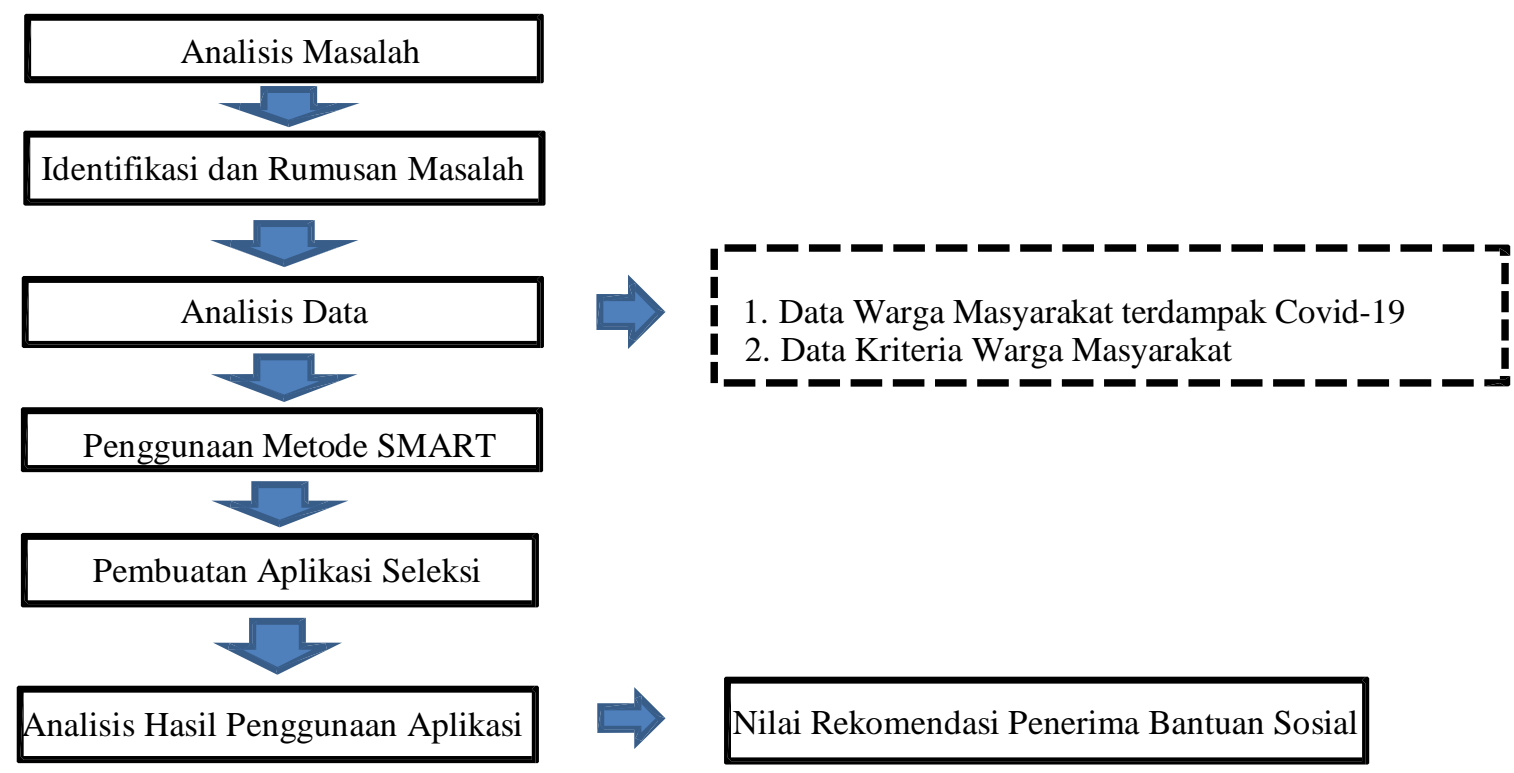

Gambar 1. Tahapan Penelitian

\section{HASIL DAN PEMBAHASAN}

Dalam penentuan penerima bantuan sosial dari PW Tabita, memiliki kriteria - kriteria setiap pegawai, adapun kriteria yaitu status pekerjaan, jumlah penghasilan perbulan, banyak tanggungan, status tempat tinggal, status tarif listrik, peserta asuransi, dan peserta PKH (Program Keluarga Harapan). Adapun Proses dalam penentuan penerima bantuan sosial dilakukan dengan memberikan bobot kriteria, data warga masyarakat, data warga masyarakat penerima bansos, sampai detail perangkingan.

\subsection{Penerapan Metode SMART}

1. Menentukan Jumlah Kriteria, Sub-Kriteria, Interval Sub-Kriteria, dan Memberikan nilai setiap kriteria

Kriteria, sub-kriteria dan interval sub-kriteria yang digunakan dalam penentuan penerima bantuan sosial kepada warga masyarakat terdampak Covid-19 dapat dilihat pada tabel 1.

Tabel 1. Kriteria, Sub-Kriteria dan Interval Sub-Kriteria dan Nilai Utility

\begin{tabular}{cccc}
\hline Kriteria & Sub-Kriteria & Interval Sub-Kriteria & $\begin{array}{c}\text { Nilai } \\
\text { Utility }\end{array}$ \\
\hline \multirow{2}{*}{ Status Pekerjaan } & Sangat Memenuhi & Pekerjaan Tidak Tetap (Hanya & 100 \\
& Memenuhi & Suami atau Istri) & 80 \\
\hline
\end{tabular}




\begin{tabular}{|c|c|c|c|}
\hline & & Istri) & \\
\hline & Cukup Memenuhi & $\begin{array}{c}\text { Pekerjaan Tetap (Hanya Suami atau } \\
\text { Istri) }\end{array}$ & 60 \\
\hline & Kurang Memenuhi & Pekerjaan Tetap ( Suami dan Istri) & 40 \\
\hline & Sangat Memenuhi & Di bawah Rp 1.000.000,- & 100 \\
\hline Penghasilan & Memenuhi & $\begin{array}{c}\text { Antara Rp } 1.000 .000,-\mathrm{s} / \mathrm{d} \mathrm{Rp} \\
2.000 .000,-\end{array}$ & 80 \\
\hline Perbulan & Cukup Memenuhi & $\begin{array}{c}\text { Antara Rp } 2.000 .000,-\mathrm{s} / \mathrm{d} \mathrm{Rp} \\
3.000 .000,-\end{array}$ & 60 \\
\hline & Kurang Memenuhi & Di atas Rp 3.000.000,- & 40 \\
\hline & Sangat Memenuhi & Lebih dari 5 orang & 100 \\
\hline Banyak & Memenuhi & Antara $3 \mathrm{~s} / \mathrm{d} 5$ orang & 80 \\
\hline Tanggungan & Cukup Memenuhi & Antara $1 \mathrm{~s} / \mathrm{d} 2$ orang & 60 \\
\hline & Kurang Memenuhi & 0 orang (Tidak ada tanggungan ) & 40 \\
\hline & Sangat Memenuhi & Sewa & 100 \\
\hline Status tempat & Memenuhi & Menumpang & 80 \\
\hline & Cukup Memenuhi & Milik sendiri & 60 \\
\hline Statu tarif lictril & Sangat Memenuhi & Tidak & 100 \\
\hline Status tarif listrik & Memenuhi & Iya & 60 \\
\hline Pecerta $A$ curanci & Sangat Memenuhi & Listrik bersubsidi & 100 \\
\hline Peserta Asuransı & Cukup Memenuhi & Listrik tidak bersubsidi & 60 \\
\hline Doconto DVU & Sangat Memenuhi & Tidak & 100 \\
\hline Peserta PКН & Cukup Memenuhi & $\mathrm{Ya}$ & 60 \\
\hline
\end{tabular}

2. Memberikan Pembobotan Kriteria dan Normalisasi Bobot Kriteria

Pembobotan nama kriteria dilakukan dengan memberikan nilai antara 0 - 100 sesuai dengan kepentingan dari masing - masing kriteria. Bobot dari masing - masing kriteria yang sudah diperoleh akan dinormalisasikan. Normalisasi dilakukan dengan membagi bobot suatu kriteria yang diperoleh dengan total bobot semua kriteria. Pembobotan Kriteria dan Normalisasi Bobot Kriteria ini dilihat pada Tabel 2.

Tabel 2. Pembobotan Kriteria dan Normalisasi Bobot Kriteria

\begin{tabular}{cccc}
\hline No. & Nama Kriteria & Nilai Kriteria & Bobot Normalisasi $(\mathbf{W j} \mathbf{j})$ \\
\hline 1 & Status Pekerjaan & 80 & 0.2 \\
2 & Jumlah penghasilan perbulan & 70 & 0.175 \\
3 & Banyak tanggungan & 60 & 0.15 \\
4 & Status tempat tinggal & 40 & 0.1 \\
5 & Status tarif listrik & 50 & 0.125 \\
6 & Peserta Asuransi & 40 & 0.1 \\
7 & Peserta PKH (Program & 60 & 0.15 \\
& Jumlah & 400 & 1.00 \\
\hline
\end{tabular}

\section{Hitung Bobot Nilai Utility Setiap Kriteria Masing - Masing.}

Adapun contoh dari penilaian terhadap warga masyarakat calon penerima bantuan sosial ditampilkan ke dalam bentuk tabel. Nilai utility keluarga warga masyarakat yaitu Kel. Suherianto, Kel. Sarinem, dan Kel. Ny. Tobing br Tambunan untuk setiap masing - masing kriteria dapat dilihat pada tabel 3.

Tabel 3. Nilai Utility Warga Calon Penerima Bantuan Sosial

\begin{tabular}{|c|c|c|c|c|}
\hline No. & $\begin{array}{l}\text { Nama } \\
\text { Pegawai }\end{array}$ & Sub-kriteria & Interval sub-kriteria & $\begin{array}{l}\text { Nilai } \\
\text { Utility }\end{array}$ \\
\hline \multirow{7}{*}{1} & \multirow{7}{*}{$\begin{array}{c}\text { Kel. } \\
\text { Suherianto }\end{array}$} & Status Pekerjaan & $\begin{array}{l}\text { Pekerjaan Tidak Tetap (Hanya } \\
\text { Suami atau Istri) }\end{array}$ & 100 \\
\hline & & Jumlah penghasilan perbulan & Rp 3.500.000,- & 60 \\
\hline & & banyak tanggungan & 5 orang & 100 \\
\hline & & Status tempat tinggal & Sewa & 100 \\
\hline & & Status tarif listrik & Subsidi & 100 \\
\hline & & Peserta asuransi & Tidak & 100 \\
\hline & & Peserta PKH & Ya & 60 \\
\hline \multirow{4}{*}{2} & \multirow{4}{*}{$\begin{array}{c}\text { Kel. } \\
\text { Sarinem }\end{array}$} & Status Pekerjaan & Pekerjaan Tetap (Suami dan Istri) & 60 \\
\hline & & Jumlah penghasilan perbulan & Rp 1.000.000,- & 100 \\
\hline & & banyak tanggungan & 0 orang & 60 \\
\hline & & Status tempat tinggal & Milik sendiri & 60 \\
\hline
\end{tabular}


JURNAL MEDIA INFORMATIKA BUDIDARMA

Volume 5, Nomor 1, Januari 2021, Page 170-185

ISSN 2614-5278 (media cetak), ISSN 2548-8368 (media online)

Available Online at https://ejurnal.stmik-budidarma.ac.id/index.php/mib

DOI 10.30865/mib.v5i1.2618

\begin{tabular}{|c|c|c|c|c|}
\hline No. & $\begin{array}{c}\text { Nama } \\
\text { Pegawai }\end{array}$ & Sub-kriteria & Interval sub-kriteria & $\begin{array}{l}\text { Nilai } \\
\text { Utility }\end{array}$ \\
\hline \multirow{10}{*}{3} & \multirow{10}{*}{$\begin{array}{l}\text { Kel. Ny. } \\
\text { Tobing br } \\
\text { Tambunan }\end{array}$} & Status tarif listrik & Tidak Subsidi & 60 \\
\hline & & Peserta asuransi & $\mathrm{Ya}$ & 60 \\
\hline & & Peserta PKH & $\mathrm{Ya}$ & 60 \\
\hline & & Status Pekerjaan & $\begin{array}{c}\text { Pekerjaan Tidak Tetap (Hanya } \\
\text { Suami atau Istri) }\end{array}$ & 100 \\
\hline & & Jumlah penghasilan perbulan & $\operatorname{Rp} 700.000,-$ & 100 \\
\hline & & banyak tanggungan & 5 orang & 100 \\
\hline & & Status tempat tinggal & Menyewa & 100 \\
\hline & & Status tarif listrik & Subsidi & 100 \\
\hline & & Peserta asuransi & Tidak & 100 \\
\hline & & Peserta PKH & $\mathrm{Ya}$ & 60 \\
\hline
\end{tabular}

Adapun proses perhitungan nilai utility penentuan warga masyarakat sebagai warga masyarakat calon penerima bantuan sosial berdasarkan contoh tabel di atas maka berikut ini adalah proses perhitungannya.

Perhitungan Nilai Utility Kel. Suherianto

a.) Status Pekerjaan $=((100-40) /(100-40)) * 100=1$

b.) Jumlah penghasilan perbulan $=((40-40) /(100-40)) * 100=0$

c.) Banyak tanggungan $=((80-60) /(80-60) * 100=1$

d.) Status tempat tinggal $=((100-60) /(100-60)) * 100=1$

e.) Status tarif listik $=((100-80) /(100-80)) * 100=1$

f.) Peserta asuransi $=((100-60) /(100-60)) * 100=1$

g.) Peserta PKH (Program Keluarga Harapan $)=((100-100) /(100-100)) * 100=0$

Perhitungan Nilai Utility Kel. Sarinem

a.) Status Pekerjaan $=((40-40) /(100-40)) * 100=0$

b.) Jumlah penghasilan perbulan $=((100-40) /(100-40)) * 100=1$

c.) Banyak tanggungan $=((60-60) /(80-60) * 100=0$

d.) Status tempat tinggal $=((60-60) /(100-60)) * 100=0$

e.) Status tarif listik $=((80-80) /(100-80)) * 100=0$

f.) Peserta asuransi $=((60-60) /(100-60)) * 100=0$

g.) Peserta PKH (Program Keluarga Harapan $)=((100-100) /(100-100)) * 100=0$

Perhitungan Nilai Utility Kel. Ny. Tobing br Tambunan

a.) Status Pekerjaan $=((100-40) /(100-40)) * 100=1$

b.) Jumlah penghasilan perbulan $=((100-40) /(100-40)) * 100=1$

c.) Banyak tanggungan $=((80-60) /(80-60) * 100=1$

d.) Status tempat tinggal $=((100-60) /(100-60)) * 100=1$

e.) Status tarif listik $=((100-80) /(100-80)) * 100=1$

f.) Peserta asuransi $=((100-60) /(100-60)) * 100=1$

g.) Peserta PKH (Program Keluarga Harapan $)=((100-100) /(100-100)) * 100=0$

Setelah nilai utility warga masyarakat sebagai penerima bantuan sosial dinormalisasikan ke tahap selanjutnya adalah menampilkan hasil normalisasi ke dalam tabel dan menghitung nilai akhir, dapat ditunjukkan pada tabel 4 sebagai berikut :

Tabel 4. Nilai Utility Warga Calon Penerima Bantuan Sosial Normalisasi

\begin{tabular}{cccc}
\hline Nama Kriteria & $\begin{array}{c}\text { Nilai Utility Kel. } \\
\text { Suherianto }\end{array}$ & $\begin{array}{c}\text { Nilai Utility Kel. Ny. } \\
\text { Sarinem }\end{array}$ & $\begin{array}{c}\text { Nilai Utility Kel. Ny. } \\
\text { Tobing br Tambunan }\end{array}$ \\
\hline Penghasilan perbulan & 1 & 0 & 1 \\
Usia & 0 & 1 & 1 \\
Jumlah tanggungan & 1 & 0 & 1 \\
Status tempat tinggal & 1 & 0 & 1 \\
Status pernikahan & 1 & 0 & 1 \\
Status tarif listrik & 1 & 0 & 1 \\
Peserta PKH & 0 & 0 & 0 \\
\hline
\end{tabular}

4. Hitung Nilai Akhir

Dimana nilai bobot kriteria yang sudah dinormalisasi dikalikan dengan nilai utility yang sudah dinormalisasi. Adapun proses perhitungan nilai akhir dari penentuan warga jemaat penerima bantuan sosial adalah sebagai berikut : 
ISSN 2614-5278 (media cetak), ISSN 2548-8368 (media online)

Available Online at https://ejurnal.stmik-budidarma.ac.id/index.php/mib DOI 10.30865/mib.v5i1.2618

Nilai Akhir Kel. Suherianto $=($ bobot Penghasilan perbulan $*$ bobot nilai utility Penghasilan perbulan $)+($ bobot Usia * bobot nilai Usia) + (bobot Jumlah tanggungan * bobot nilai Jumlah tanggungan) + (bobot Status tempat tinggal $*$ bobot nilai Status tempat tinggal $)+($ bobot Status pernikahan * bobot nilai Status pernikahan $)+($ bobot Status tarif listrik * bobot nilai Status tarif listrik $)+($ bobot Peserta PKH * bobot nilai Peserta PKH)

Nilai Akhir $=(0.2 * 1)+(0.175 * 0)+(0.15 * 1)+(0.1 * 1)+(0.125 * 1)+(0.1 * 1)+(0.15 * 0)=0.675$

Nilai Akhir Kel. Sarinem = (bobot Penghasilan perbulan * bobot nilai utility Penghasilan perbulan $)+($ bobot Usia * bobot nilai Usia) + (bobot Jumlah tanggungan * bobot nilai Jumlah tanggungan) + (bobot Status tempat tinggal * bobot nilai Status tempat tinggal $)+($ bobot Status pernikahan * bobot nilai Status pernikahan $)+($ bobot Status tarif listrik * bobot nilai Status tarif listrik) + (bobot Peserta PKH * bobot nilai Peserta PKH)

Nilai Akhir $=(0.2 * 0)+(0.175 * 1)+(0.15 * 0)+(0.1 * 0)+(0.125 * 0)+(0.1 * 0)+(0.15 * 0)=0.175$

Nilai Akhir Kel. Ny. Tobing br Tambunan = (bobot Penghasilan perbulan * bobot nilai utility Penghasilan perbulan $)+($ bobot Usia * bobot nilai Usia $)+($ bobot Jumlah tanggungan * bobot nilai Jumlah tanggungan $)+$ (bobot Status tempat tinggal * bobot nilai Status tempat tinggal) + (bobot Status pernikahan * bobot nilai Status pernikahan $)+($ bobot Status tarif listrik * bobot nilai Status tarif listrik) + (bobot Peserta PKH * bobot nilai Peserta PKH)

Nilai Akhir $=(0.2 * 1)+(0.175 * 1)+(0.15 * 1)+(0.1 * 1)+(0.125 * 1)+(0.1 * 1)+(0.15 * 0)=0.85$

Berdasarkan perhitungan di atas, maka diperoleh hasil bahwa:

a.) Kel. Suherianto, nilainya 0.675 sehingga memperoleh bukan nilai akhir tertinggi namun masih berada di range nilai kandidat, sehingga berhak memperoleh bantuan sosial.

b.) Kel. Sarinem, nilainya 0.175 bukan nilai tertinggi sehingga tidak dipilih sebagai penerima bantuan sosial.

c.) Kel. Ny. Tobing br Tambunan, nilainya 0.85 sehingga memperoleh nilai akhir tertinggi, sehingga berhak memperoleh bantuan sosial.

Hasil akhir dari perhitungan warga sebagai penerima bantuan sosial tersebut adalah berdasarkani tabel keputusan ditunjukkan pada tabel 5 sebagai berikut:

Tabel 5. Tabel Keputusan

\begin{tabular}{cll}
\hline No. & Nilai & Keterangan \\
\hline 1. & $0 \mathrm{~s} / \mathrm{d} \mathrm{0,45}$ & Tidak direkomendasikan untuk mendapatkan Bantuan sosial \\
2. & $0,46 \mathrm{~s} / \mathrm{d} \mathrm{0,65}$ & Dapat untuk dipertimbangkan mendapatkan Bantuan sosial \\
3. & $0,66 \mathrm{~s} / \mathrm{d} 1$ & Direkomendasikan agar mendapatkan Bantuan sosial \\
\hline
\end{tabular}

\subsection{Rancangan Sistem}

\section{a. Use Case Diagram Usulan}

Adapun bentuk Desain Sistem terdiri dari Use Case Diagram, Class Diagram, Activity Diagram dan Sequency Diagram dari metode Simple Multi Attribute Rating Technique (SMART) dapat dilihat pada gambar 2 di bawah ini :

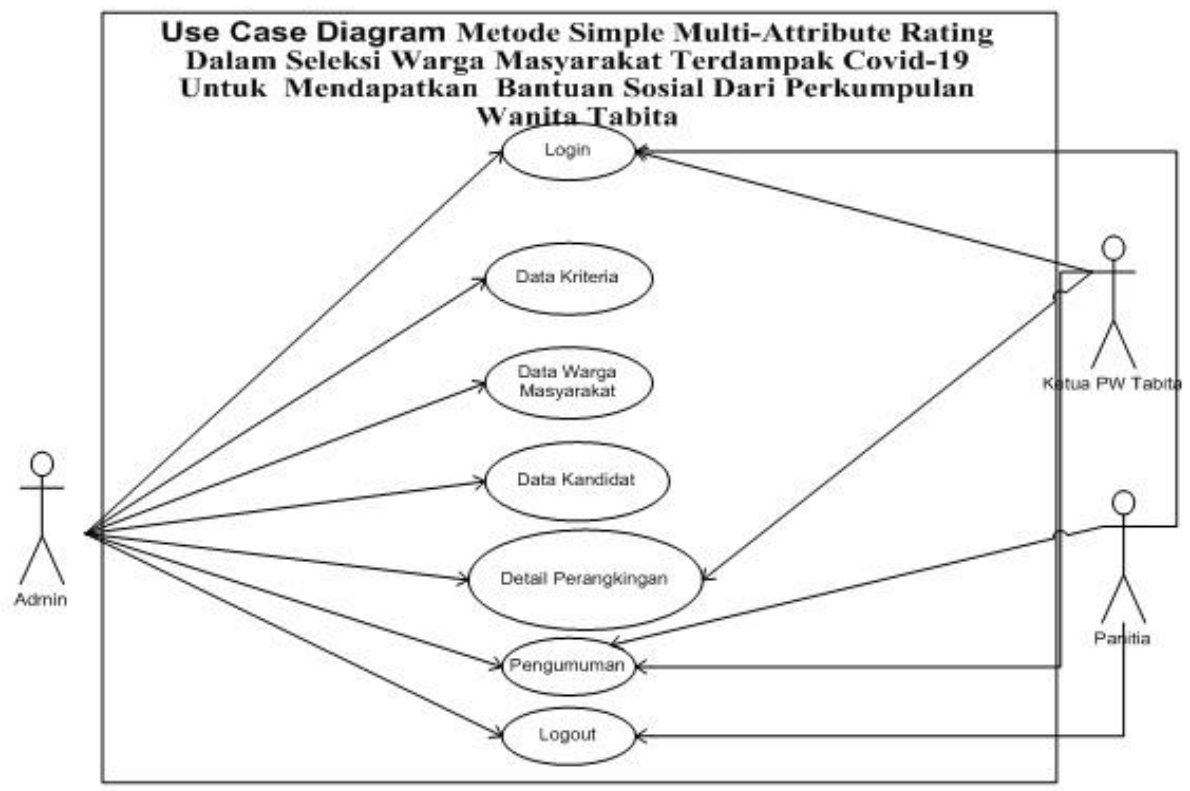

Gambar 2. Use Case Diagram Usulan 
JURNAL MEDIA INFORMATIKA BUDIDARMA

Volume 5, Nomor 1, Januari 2021, Page 170-185

ISSN 2614-5278 (media cetak), ISSN 2548-8368 (media online)

Available Online at https://ejurnal.stmik-budidarma.ac.id/index.php/mib

DOI 10.30865/mib.v5i1.2618

Definisi Aktor

Tabel 6. Defenisi Aktor Use Case Usulan

\begin{tabular}{lll}
\hline No & \multicolumn{1}{c}{ Aktor } & \multicolumn{1}{c}{ Penjelasan } \\
\hline 1 & Admin & $\begin{array}{l}\text { Orang yang mengelola data jemaat dan data warga masyarakat yang } \\
\text { diusulkan untuk penerima bantuan sosial. }\end{array}$ \\
2 & Ketua PW Tabita & $\begin{array}{l}\text { Orang yang mengesahkan nama warga masyarakat penerima bantuan sosial. } \\
\text { Orang yang mengusulkan nama warga masyarakat sebagai Warga Calon } \\
\text { Panitia }\end{array}$ \\
\end{tabular}

Berikut pada tabel 7, daftar Use Case.

Tabel 7. Defenisi Use Case Usulan

\begin{tabular}{|c|c|c|}
\hline No & Use Case & Penjelasan \\
\hline 1 & Login & $\begin{array}{l}\text { Admin, Ketua PW Tabita, dan Panitia harus memasukkan username dan } \\
\text { password yang sesuai untuk bisa masuk ke sistem. }\end{array}$ \\
\hline 2 & Data Kriteria & $\begin{array}{l}\text { Setelah login admin melakukan proses input data kriteria dan nilai bobot } \\
\text { kriteria. }\end{array}$ \\
\hline 3 & Data Jemaat & $\begin{array}{l}\text { Admin mengentri data warga masyarakat yang meliputi, NIK (Nomor Induk } \\
\text { Kependudukan), status pekerjaan, jumlah penghasilan perbulan, banyak } \\
\text { tanggungan, status tempat tinggal, Status tarif listrik, peserta asuransi, dan } \\
\text { peserta PKH (Program Keluarga Harapan) }\end{array}$ \\
\hline 4 & $\begin{array}{l}\text { Data Warga Calon } \\
\text { Penerima }\end{array}$ & $\begin{array}{l}\text { Admin memilih warga masyarakat yang akan dijadikan Warga Calon } \\
\text { Penerima/Warga Calon Penerima bantuan sosial. }\end{array}$ \\
\hline 5 & $\begin{array}{l}\text { Detail } \\
\text { Perangkingan }\end{array}$ & $\begin{array}{l}\text { Menampilkan proses perhitungan nilai bobot kriteria untuk mendapatkan } \\
\text { nilai akhir untuk dapat dirangking. }\end{array}$ \\
\hline 6 & Pengumuman & $\begin{array}{l}\text { Admin membuat laporan yang akan diberikan kepada Ketua PW Tabita } \\
\text { setelah dilakukan proses perangkingan }\end{array}$ \\
\hline 7 & Logout & Keluar dari sistem \\
\hline
\end{tabular}

b. Class Diagram

Untuk perancangan aplikasi ini dibuat penggambaran setiap objeknya secara lengkap dengan memiliki attribut. Berikut ini adalah rancangan class diagram sistem yang baru pada gambar 3 di bawah ini:

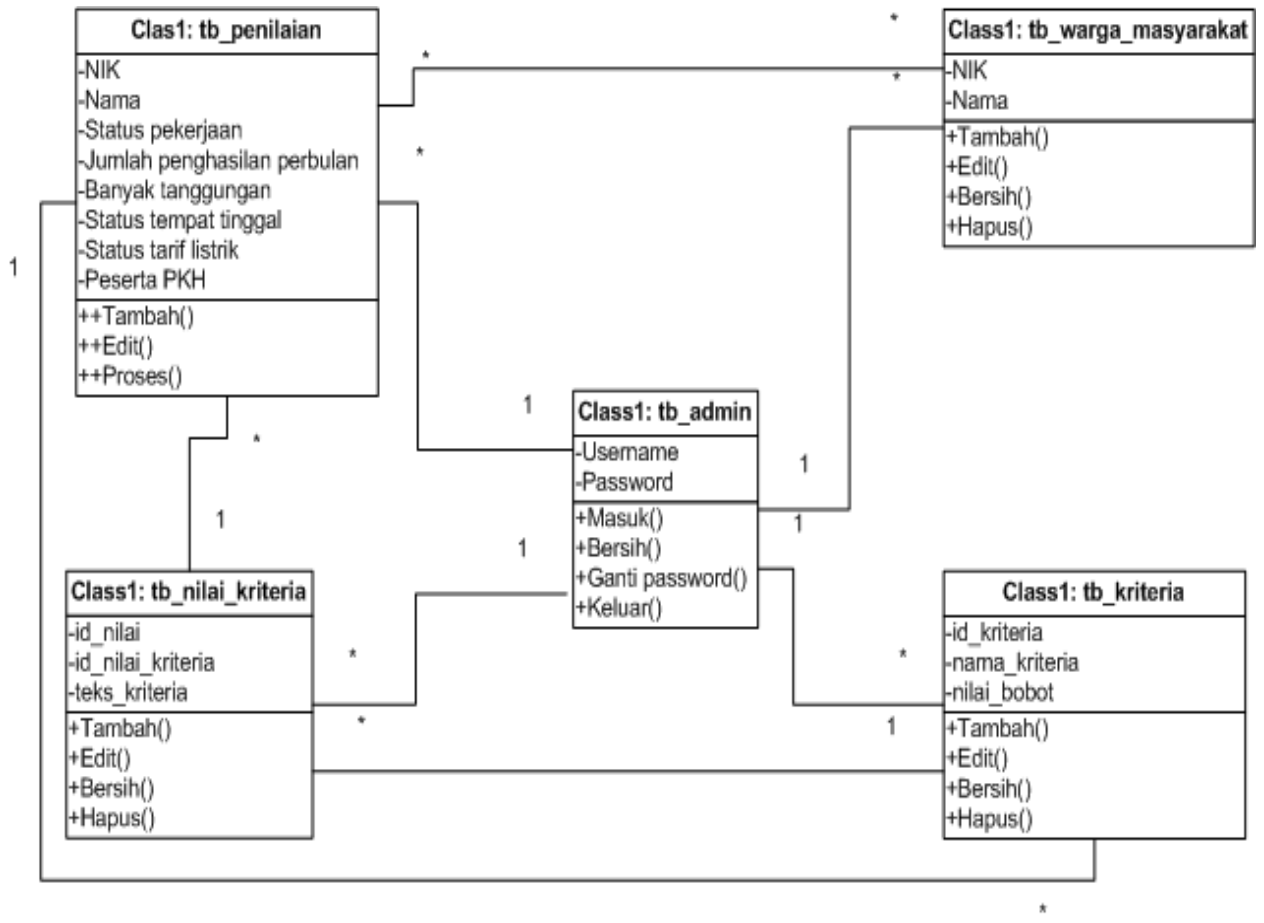

Gambar 3. Class Diagram

\section{c. Activity Diagram}

Activity Diagram pada aplikasi Sistem Pendukung Keputusan Pemilihan Penerima Bantuan Sosial dari PW (Perkumpulan Wanita) Tabita bagi warga masyarakat terdampak Covid-19 adalah sebagai berikut ini. 
JURNAL MEDIA INFORMATIKA BUDIDARMA

Volume 5, Nomor 1, Januari 2021, Page 170-185

ISSN 2614-5278 (media cetak), ISSN 2548-8368 (media online)

Available Online at https://ejurnal.stmik-budidarma.ac.id/index.php/mib DOI 10.30865/mib.v5i1.2618

1. Activity Diagram Form Data Kriteria

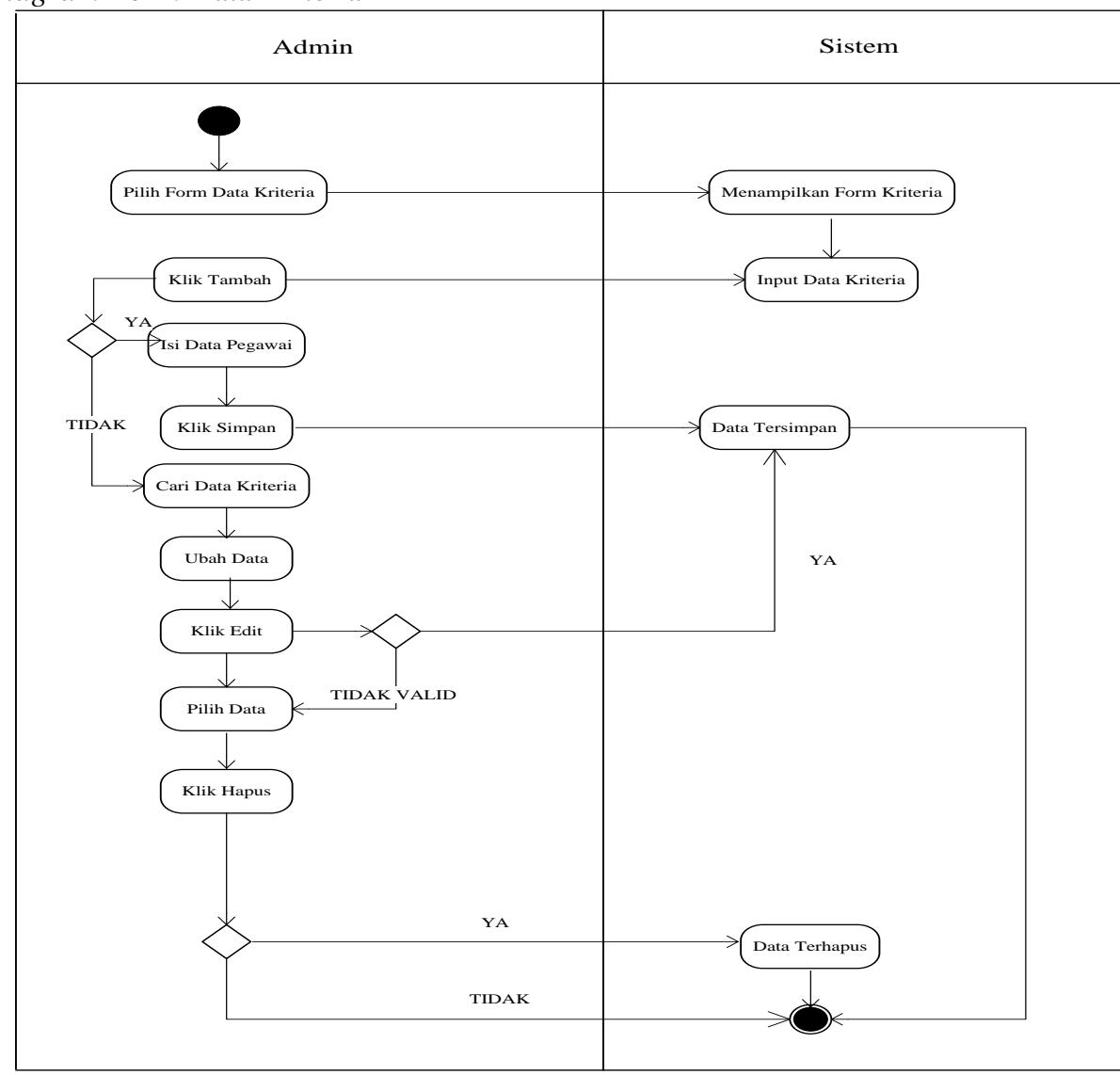

Gambar 4. Activity Diagram Form Data Kriteria

Pada Activity Diagram Form Data Kriteria, Admin melakukan aktifitas mengentri data kriteria yang terdiri dari nama ID kriteria, nama kriteria, dan bobot kriteria. Di dalam jendela Form Data Kriteria terdapat fasilitas Tambah, Edit, dan Hapus Data Kriteria.

2. Activity Diagram Form Data Warga Masyarakat

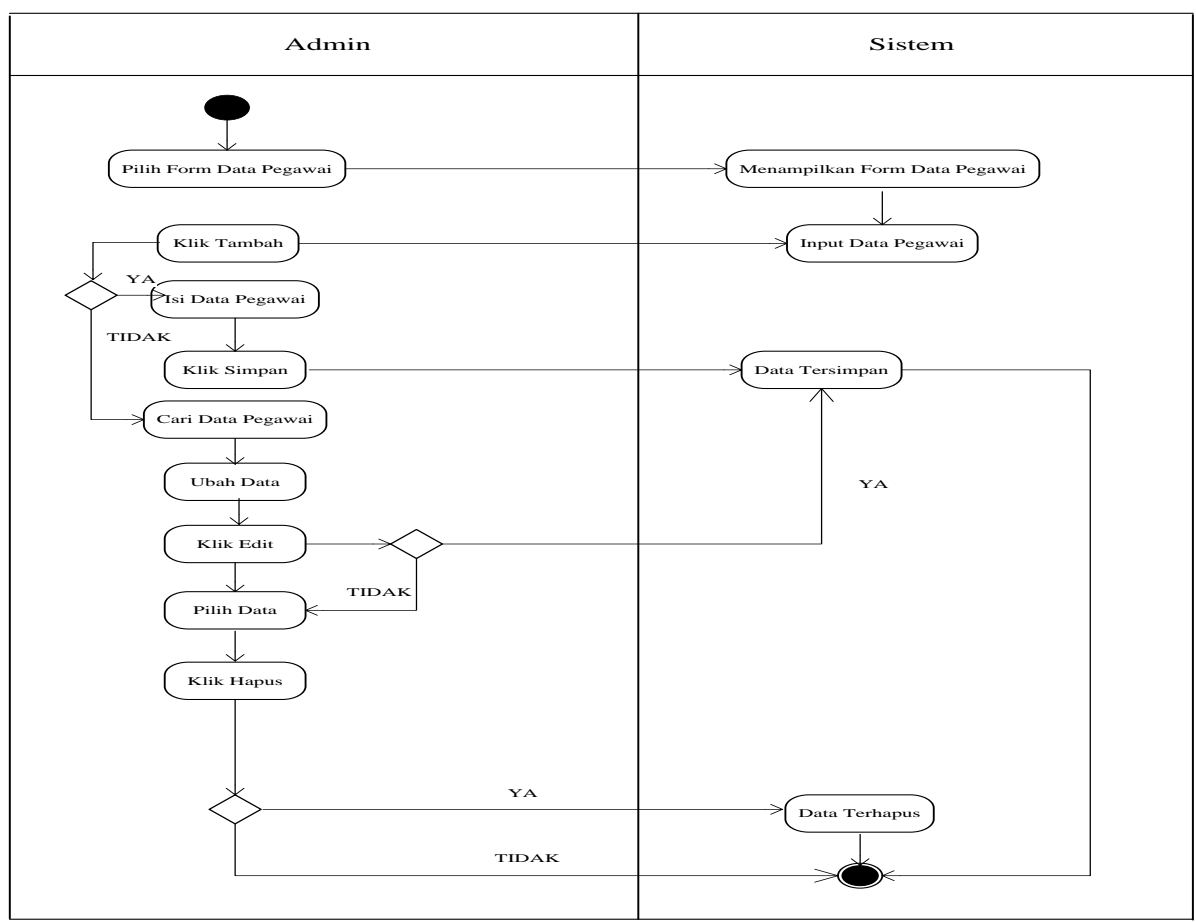

Gambar 5. Activity Diagram Form Data Warga Masyarakat

Bambang TJ Hutagalung, Copyright (C2021, MIB, Page 181 
JURNAL MEDIA INFORMATIKA BUDIDARMA

Volume 5, Nomor 1, Januari 2021, Page 170-185

ISSN 2614-5278 (media cetak), ISSN 2548-8368 (media online)

Available Online at https://ejurnal.stmik-budidarma.ac.id/index.php/mib DOI 10.30865/mib.v5i1.2618

Pada Activity Diagram Form Data Warga Masyarakat, Admin melakukan aktifitas mengentri data jemaat yang terdiri dari NIK (Nomor Induk Kependudukan), Nama, status pekerjaan, jumlah penghasilan perbulan, banyak tanggungan, status tempat tinggal, Status tarif listrik, peserta asuransi, dan peserta PKH (Program Keluarga Harapan). Di dalam jendela Form Data Warga Masyarakat terdapat fasilitas Tambah, Edit, dan Hapus Data Warga Masyarakat.

3. Activity Diagram Form Data Warga Masyarakat Calon Penerima Bantuan Sosial

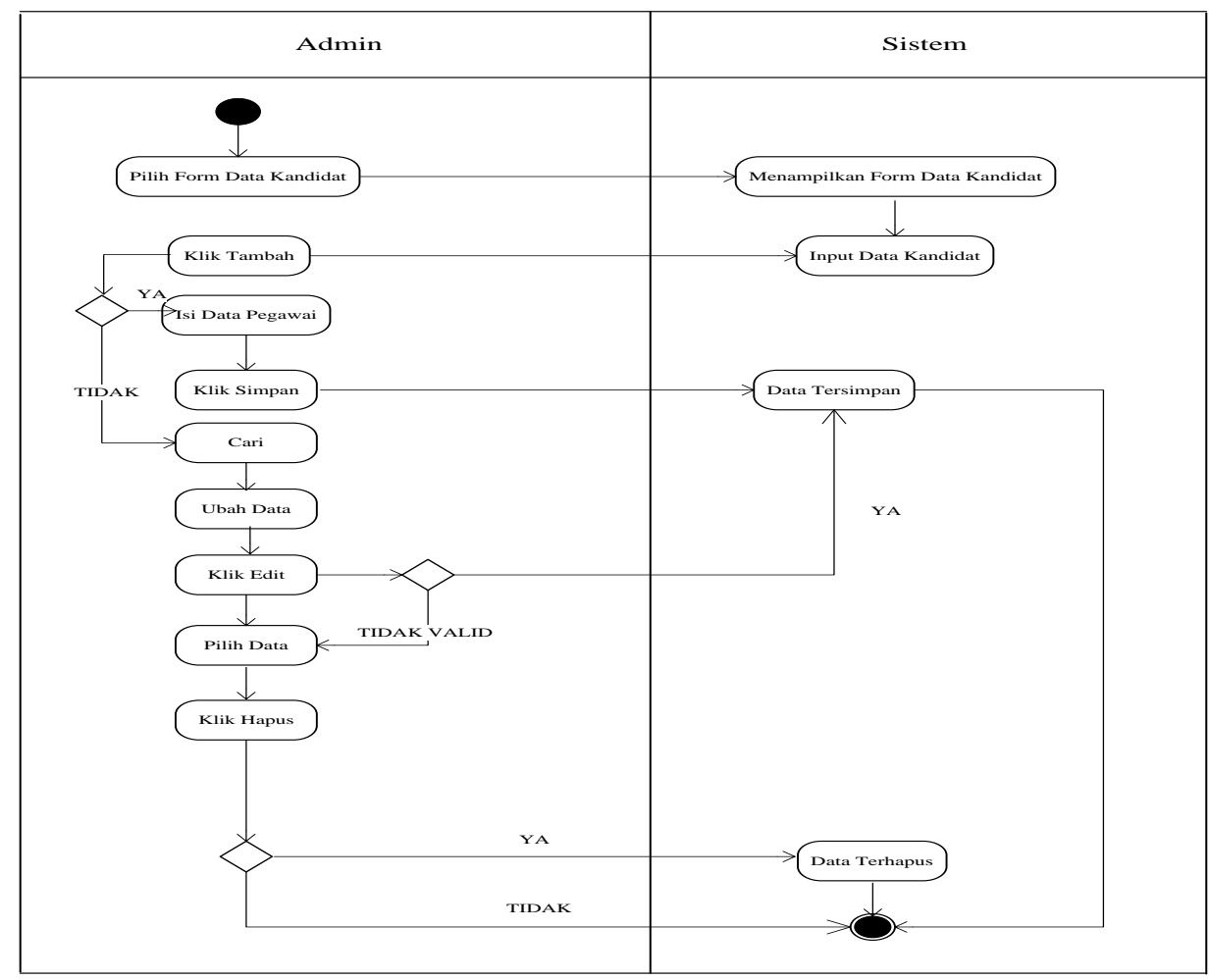

Gambar 6. Activity Diagram Form Data Warga Calon Penerima Bantuan Sosial

Pada Activity Diagram Form Data Warga Calon Penerima Bantuan Sosial, Admin melakukan aktifitas memilih data warga masyarakat yang akan diseleksi sebagai calon Penerima bantuan sosial. Di dalam jendela Form Data Warga Calon Penerima Bantuan Sosial terdapat fasilitas Tambah, Edit dan Hapus Data.

4. Activity Diagram Form Detail Perangkingan

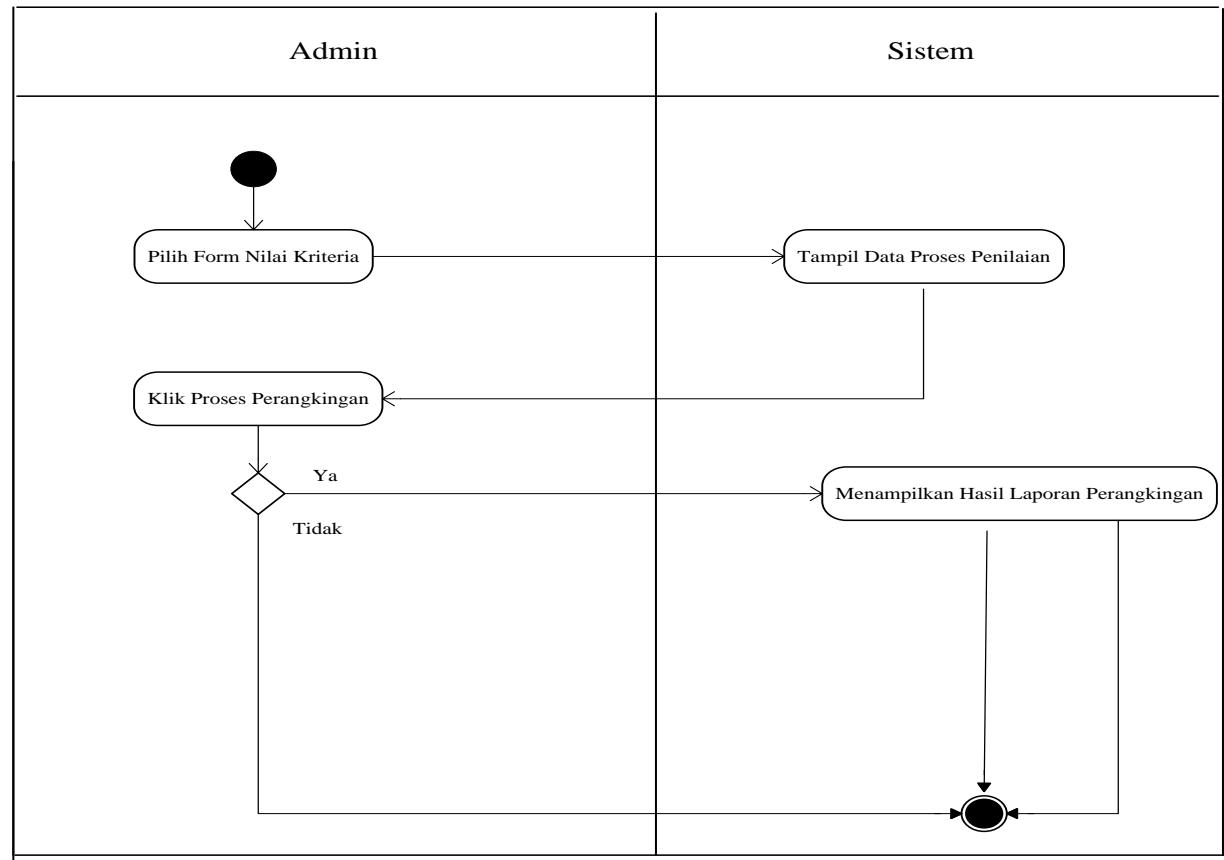

Gambar 7. Activity Diagram Form Detail Perangkingan

Bambang TJ Hutagalung, Copyright $(\mathrm{2} 2021$, MIB, Page 182 
Pada Activity Diagram Form Data Warga Calon Penerima Bantuan Sosial, Admin melakukan aktifitas menekan tombol proses perangkingan bobot kriteria Data Warga Calon Penerima. Di dalam jendela Form Detail perangkingan, hanya menampilkan detail perhitungan bobot kriteria Warga calon penerima bantuan sosial dan proses perangkingan.

\subsection{Implementasi Program}

Berikut ini dijelaskan tentang tampilan hasil dari Penerapan Metode Simple Multi Attribute Rating Technique (SMART) dalam penentuan jemaat sebagai penerima bantuan sosial dari PW Tabita pada GKPI JK Pulo Brayan. Tampilan pengujian aplikasi ini berupa Tampilan form login, menu utama, form data kriteria, formdata jemaat, form data Warga Calon Penerima, form detail perangkingan dan detail pengumuman. Berikut ini adalah beberapa tampilan pada aplikasi ini :

1. Tampilan menu Data Warga Calon Penerima

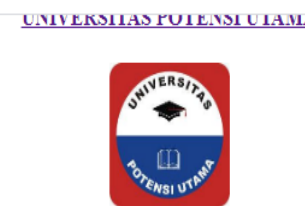

Anda login sebagai: admin Data Kriteria Data Warga Masyarakat Data Calon Penerima Bantuan Detail Perangkingan pengumuman Logout

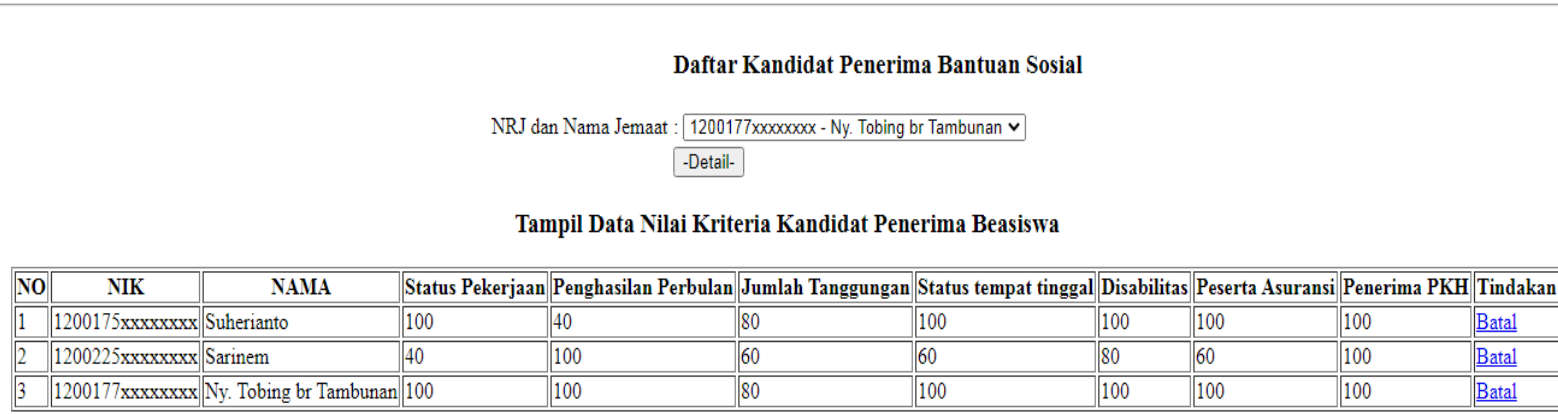

Tampil Data Nilai Utility Kandidat Penerima Bantuan Sosial

\begin{tabular}{|l|l|l|l|l|l|l|l|l|l||}
\hline N0 & \multicolumn{1}{|c|}{ NRJ } & \multicolumn{1}{|c|}{ NAMA } & K01 & K02 & K03 & K04 & K05 & K06 & K07 \\
\hline 1 & $1200175 \times x \times x \times x x$ & Suherianto & 100 & 40 & 80 & 100 & 100 & 100 & 100 \\
\hline 2 & $1200225 \times x \times x \times x x x$ & Sarinem & 40 & 100 & 60 & 60 & 80 & 60 & 100 \\
\hline 13 & $1200177 \times x \times x x x x x$ & Ny. Tobing br Tambunan & 100 & 100 & 80 & 100 & 100 & 100 & 100 \\
\hline
\end{tabular}

Gambar 8. Tampilan Menu Data Warga Masyarakat

2. Tampilan Hasil Form Detail Perangkingan

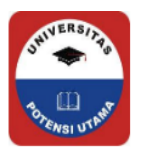

Anda login sebagai: admin Data Kriteria Data Warga Masyarakat Data Calon Penerima Bantuan Detail Perangkingan pengumuman Logout

PERHITUNGAN NILAI UTILITY CALON PENERIMA BANTUAN SOSIAL BAGI WARGA MASYARAKAT TERDAMPAK COVID-19

1. PROSES PERHITUNGAN :

NIP : $1200175 \times x \times x x x x x$

Nama : Suherianto

Bobot Nilai Utility berdasarkan

a.) Status Pekerjaan $=((100-40) /(100-40)) * 100=1$

b.) Jumlah penghasilan perbulan $=((40-40) /(100-40)) * 100=0$

b.) Jumlah penghasilan perbulan $=((40-40)(100-40))$

c.) Banyak tanggungan $=((80-60) /(80-60) * 100=1$
d.) Status tempat tinggal $=((100-60) /(100-60)) * 100=1$

d.) Status tempat tinggal $=((100-60) /(100-60)) * 100$
e.) Status tarif listik $=((100-80) /(100-80)) * 100=1$

e.) Status tarif listik $=((100-80) /(100-80)) * 100=1$
f.) Peserta asuransi $=((100-60) /(100-60)) * 100=1$

f.) Peserta asuransi $=((100-60) /(100-60)) * 100=1$
g.) Peserta PKH (Program Keluarga Harapan $)=((100-100) /(100-100)) * 100=0$

g.) Peserta PKH (Program Keluarga Harapan $)=(((100-100) /(100-100)) * 100=0$
Nilai Akhir $=\left(0.2^{*} 1\right)+\left(0.175^{*} 0\right)+\left(0.15^{*} 1\right)+(0.1 * 1)+\left(0.125^{*} 1\right)+\left(0.1^{*} 1\right)+\left(0.15^{*} 0\right)=0.675$

2. PROSES PERHITUNGAN :

NIP : $1200225 \times x \times x \times x x x$

Nama : Sarinem

Bobot Nilai Utility berdasarkan

a.) Status Pekerjaan $=((40-40)(100-40)) * 100=0$

b.) Jumlah penghasilan perbulan $=((100-40) /(100-40)) * 100=1$

c.) Banyak tanggungan $=((60-60) /(80-60) * 100=0$

d.) Status tempat tingal $=((60-60)(100-60)) * 100=0$

e.) Status tarif listik $=((80-80) /(100-80)) * 100=0$

Gambar 9. Tampilan Form Detail Perangkingan 
JURNAL MEDIA INFORMATIKA BUDIDARMA

Volume 5, Nomor 1, Januari 2021, Page 170-185

ISSN 2614-5278 (media cetak), ISSN 2548-8368 (media online)

Available Online at https://ejurnal.stmik-budidarma.ac.id/index.php/mib

DOI 10.30865/mib.v5i1.2618

3. Tampilan Menu Pengumuman

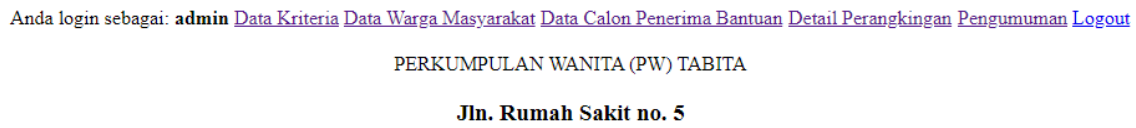

DAFTAR KANDIDAT PENERIMA BANTUAN SOSIAL BAGI MASYARAKAT TERDAMPAK COVID-19

\begin{tabular}{|l|l|l||l|l|}
\hline NO & \multicolumn{1}{|c|}{ NIP } & \multicolumn{1}{|c|}{ Nama } & Nilai Akhir & \multicolumn{1}{|c|}{ Hasil Akhir } \\
\hline 1 & $1200175 \times \mathrm{xxxxxxx}$ & Suherianto & 0.675 & Sangat berhak mendapatkan bantuan sosial \\
\hline 2 & $1200225 \mathrm{xxxxxxxx}$ & Sarinem & 0.175 & Tidak berhak mendapatkan bantuan sosial \\
\hline 3 & $1200177 \times \mathrm{xxxxxxxx}$ & Ny. Tobing br Tambunan & 0.85 & Sangat berhak mendapatkan bantuan sosial \\
\hline \hline
\end{tabular}

Untuk bentuk printout, silahkan klik tombol CETAK

Diketahui Oleh

Ketua Perkumpulan Wanita (PW) Tabita

(Janisah Hanum br Manik)

Gambar 10. Tampilan Form Pengumuman

\section{KESIMPULAN}

Dengan menggunakan metode Simple Multy Atributte Rating Technique (SMART) dapat diketahui detail hasil perhitungan bahwa warga masyarakat terdampak Covid-19 yang sangat layak untuk mendapatkan bantuan dana sosial dengan penilaian akhir di atas 0,66 dengan rekomendasi sangat layak. Selain itu penentuan bobot yang tepat pada setiap kriteria sangat mempengaruhi hasil perhitungan terhadap rekomendasi pemberian bantuan dana sosial bagi masyarakat terdampak Covid-19. Untuk dapat memperoleh hasil yang lebih akurat maka perlu dilakukan uji validitas terhadap kriteria untuk memperoleh kriteria yang lebih tepat sesuai dengan kebutuhan seleksi kelayakan penerima bantuan dana sosial bagi warga masyakat terdampak Covid-19 dari PW Tabita.

\section{UCAPAN TERIMA KASIH}

Penulis mengucapkan terima kasih kepada kepada Kementerian RISTEK-BRIN yang telah mendanai penelitian ini melalui pemberian Hibah Penelitian pada skema Penelitian Dosen Pemula pendanaan 2020 dengan No. SK: B/87/E3/RA.00/2020.

\section{REFERENCES}

[1] S. Abednego Dwi Septiadi, "Implementation of Analytical Hierarch Process Method," TEKNOMATIKA, vol. 08, no. 01, pp. 15-22, 2018

[2] M. Fahmi Setiawan, Fatma Indriani, "Implementasi Metode Electre Pada Sistem Pendukung Keputusan SNMPTN Jalur Undangan,” Kumpul. J. Ilmu Komput., vol. 02, no. 02, pp. 88-101, 2015.

[3] M. Guntur and R. Yanto, "Penerapan Metode SMART untuk Seleksi Kelayakan Penerima Bantuan Pengembangan Usaha Pangan Masyarakat,” Telematika, vol. 12, no. 2, pp. 149-159, 2019, doi: 10.35671/telematika.v12i2.826.

[4] B. T. Hutagalung and E. T. Siregar, "Metode Simple Multi-Attribute Rating dalam Seleksi Kelayakan Penerima Bantuan Sosial di Perkumpulan Wanita Tabita," TEKNOMATIKA, vol. 10, no. 02, pp. 151-162, 2020, [Online]. Available: http://ojs.palcomtech.ac.id/index.php/teknomatika/article/view/502/359.

[5] M. Mesran, A. Rizki, and N. Silalahi, "Application of Multi Criteria Supporting Elemination and Choice Translation Reality (ELECTRE) Decision in Determining Scholarship Recipients for Employee Children at PT. Nusira," IJICS (International J. Informatics Comput. Sci., vol. 3, no. 1, pp. 15-23, 2019.

[6] A. J. Nasution, "Multi Attribute Rating Technique (Smart)," J. Pelita Inform., vol. 18, pp. 482-487, 2019.

[7] N. Nurhasanah, "Pendukung Keputusan Penentuan Penerima Beasiswa Menggunakan Metode Smart ( Simple Multi Attribute Rating Technique )," Maj. Ilm. INTI, vol. XII, no. 1, pp. 60-66, 2017.

[8] I. Pahwi, B. Nadeak, and I. Lubis, "SISTEM PENDUKUNG KEPUTUSAN PEMILIHAN RESELLER BUKU PAKET PADA SMA BHAYANG KARI MEDAN MENGGUNAKAN METODE SMART,” J. Pelita Inform., vol. 16, pp. 385390, 2017.

[9] M. Safii and D. Anggi Saputri, "Penerapan Metode Simple Multi Attribute Rating Technique (Smart) Sebagai Motivasi Pegawai Dalam Peningkatan Prestasi," J. Mantik Penusa, vol. 2, no. 2, pp. 169-174, 2018, [Online]. Available: http://ejurnal.pelitanusantara.ac.id/index.php/mantik/article/view/496.

[10] A. Saleh, "Penerapan Metode Simple Multi Attribute Rating Technique Exploiting Rank dalam Sistem Pendukung Keputusan Rekrutmen Asisten Laboratorium Komputer," Masy. Telemat. dan Inf., vol. 8, pp. 1-10, 2018.

[11] Supriyadi, "Sistem Pendukung Keputusan Untuk Penerimaan Karyawan Baru Dengan Metode Smart ( Simple Multi Attribute Rating Technique ) Di Pt Etowa Packaging Indonesia,” J. Chem. Inf. Model., vol. 53, no. 9, pp. 1689-1699, 2018 . 
JURNAL MEDIA INFORMATIKA BUDIDARMA

Volume 5, Nomor 1, Januari 2021, Page 170-185

ISSN 2614-5278 (media cetak), ISSN 2548-8368 (media online)

Available Online at https://ejurnal.stmik-budidarma.ac.id/index.php/mib

DOI 10.30865/mib.v5i1.2618

[12] S. Suryanto and M. Safrizal, "Sistem Pendukung Keputusan Pemilihan Karyawan Teladan dengan Metode SMART (Simple Multi Attribute Rating Technique)," J. CoreIT, vol. 1, no. 2, pp. 25-29, 2015.

[13] Y. E. Windarto, I. P. Windasari, and M. A. M. Arrozi, "Implementasi Simple Multi Attribute Rating Technique Untuk Penentuan Tempat Pembuangan Akhir," J. Pengemb. Rekayasa dan Teknol., vol. 15, no. 1, p. 12, 2019, doi: 10.26623/jprt.v15i1.1484. 